\title{
Mechanical properties of composite material laminates reinforced by woven and non-woven glass fibers
}

\author{
Amer Karnoub ${ }^{1}$, Hajian Huang ${ }^{1}$, Imad Antypas ${ }^{2, *}$ \\ ${ }^{1}$ Institute of Polymers, ETH Zurich, 8093, Zurich, Switzerland \\ ${ }^{2}$ Don State Technical University, 1, Gagarin square, 344000, Rostov-on-Don, Russia
}

\begin{abstract}
The purpose of this work is to study the mechanical characteristics in 3-point bending and in traction; static; and the impact behavior of three specimens of laminates made of glass fiber and polyester resin non-woven and woven, with the aim of using them in the repair of boat hulls and enhancing their value in the naval industry. Three types of laminates were developed by contact molding. These different specimens of laminates made of woven, non-woven and combined glass fiber (woven and non-woven) were subjected to mechanical tests (traction and 3-point bending). Analysis of the results of the tests carried out on these three types of laminate shows that one specimen stands out and gives higher mechanical performance than the other two.
\end{abstract}

\section{Introduction}

In recent years, the composite materials processing industry has enjoyed rapid and steady growth, supported in particular by the diversity of applications [1-2]. Due to their properties of lightness, rigidity and specific resistance, composite materials are used today in a growing number of applications, in increasingly wide fields, ranging from aerospace research to large sporting goods public [3].

In the field of materials testing, the dependable, reproducible quantitative portrayal of physical properties, specifically mechanical properties, is an issue. Simultaneously, this is additionally a specific test [4-5]. When all is said in done, polymer composites strengthened with the fibers are typically one to multiple times more grounded and stiffer than their unfilled frameworks [6,7]. The compressive and elastic reactions of glass fiber-strengthened polymer composites, including those of woven glass fiber-fortified polymer composites, have been the subjects of proceeded with examination $[8,9]$. Numerous components influence the compressive and elastic conduct of woven glass fiber-strengthened polymer composite materials [10], for instance the material utilized, kind of weave texture geometry, fiber volume portion cover configuration void substance and woven direct thickness in which the most significant elements are the mechanical properties of the fiber and the lattice [11-13]. Since impacts can cause significant reductions in stiffness of composite structures, it is essential to study the impact behavior of composite materials [14].

*Corresponding author: Imad.antypas@mail.ru 
Our study involves the development of three specimens of laminated composite materials, their characterization by mechanical tests.

The results obtained allow us to choose the type of laminate that is best suited for repairing and manufacturing the hulls of fishing boats.

\section{Materials of the study}

Three types of laminates are produced in the materials and composites mechanics laboratory of the Materials, Process and Environment Research Unit, made of glass fibers (non-woven and woven) and polyester resin. These differ in the number of plies and the structure of the glass fibers.

\subsection{Fiberglass}

\subsubsection{Chemical composition}

The composition of the glass intended for textile fibers is very different from that used for common glasses. The fibers must be able to resist attack by chemical agents and have an exceptionally high mechanical tensile strength.

Their composition, very poor in alkaline oxides, contains significant amounts of alumina, boric anhydride and alkaline earth oxides.

Table 1. Chemical composition of the glass used as a reinforcement.

\begin{tabular}{|l|c|c|c|c|}
\hline Chemical composition of the glass & $\mathbf{S i O 2}$ & $\mathbf{B}_{\mathbf{2}} \mathbf{O}_{\mathbf{3}}$ & $\mathbf{A l}_{\mathbf{2}} \mathbf{O}_{\mathbf{3}}$ & $\mathbf{C a O}$ \\
\hline Content in\% & 55.5 & 8.1 & 14 & 21 \\
\hline
\end{tabular}

We used two types of glass fibers (non-woven and woven).

\subsubsection{Non-woven glass fabric}

There are several types of non-woven glass fabric, in our work we used the fabric of 450 $\mathrm{g} / \mathrm{m} 2$ weight.

\subsubsection{Woven glass fabric}

Also we choose the same weight for woven glass fabric, using plain $1 / 1$ weave structure (Tafta).

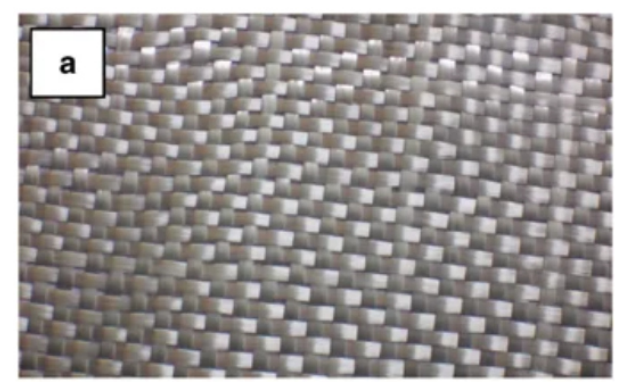

a - Woven glass fabric

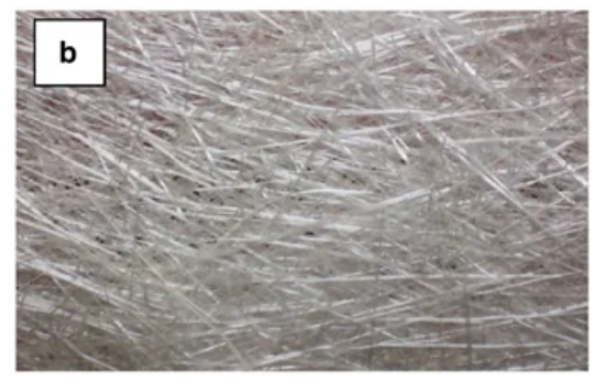

b - Non-woven glass fabric

Fig. 1. woven and non-woven glass fabric. 


\subsection{Unsaturated polyester resin}

Polyester resins are thermosetting plastics, a synthetic resin is generally composed of two chemically different products whose association is complementary. The first is the resin itself, an open polymer chain with a rather viscous tendency and an almost colorless. The second is the catalyst has the effect of closing the polymer chains entirely contained in the resin (hence the small amount of catalyst to add about $1 \%$ ).

Table 2. Characteristics of polyester resins according to the technical sheet.

\begin{tabular}{|l|c|}
\hline Monomer content & $39 \%$ \\
\hline PMEC catalyst (50\%) & $1.5 \%$ \\
\hline Freezing time & $18 \mathrm{~min}$ \\
\hline Exothermic freezing time & $15 \mathrm{~min}$ \\
\hline Water absorption & $0.15 \%$ ASTM D570 \\
\hline Elastic tensile limit & $600 \mathrm{Kg} / \mathrm{cm}^{2}$ ASTM D638 \\
\hline Bending force & $1050 \mathrm{Kg} / \mathrm{cm}^{2}$ ASTM D790 \\
\hline Elongation at break & $1.9 \%$ \\
\hline
\end{tabular}

\subsection{Preparation of laminates}

The 300 x $300 \mathrm{~mm}$ laminate sheets are made by contact molding, and pressed between two wooden sheets using a filler. The molds are removed from the mold after twelve hours. Then the latter are stored at room temperature for 20 days, until the resin has completely polymerized. The test pieces are cut using a diamond disc saw and lubricated according to standard NF T 57-153.

The different laminates produced are made up as follows:

- $\quad$ Specimen 1st: 6 folds (100\% woven);

- Specimen 2nd: 2 non-woven folds + 5 woven folds;

- $\quad$ Specimen 3rd: 14 folds (100\% non-woven).

\section{Mechanical tests}

The mechanical tests were carried out on a Zwick universal machine, type Z250 equipped with testXpert V9.0 software and equipped with a $2.5 \mathrm{KN}$ force sensor. Piloting and acquisition are done by computer.

In tension and bending, at least five test pieces are required for each type of laminate with different test speeds according to the standards in force.

\subsection{Tensile test}

The laminates obtained are cut into test pieces according to ISO standard 527-5 using a diamond disc and cooled with water. Heels are stuck on the ends of the test pieces as stipulated in the standard.

Table 3. Mechanical features in tensile test for specimens.

\begin{tabular}{|l|c|c|c|}
\hline \multicolumn{1}{|c|}{ Specimen No. } & $\mathbf{1}$ & $\mathbf{2}$ & $\mathbf{3}$ \\
\hline YOUNG module $\left(\mathrm{E}_{\mathrm{t}}\right)$ in $\mathrm{GPa}$ & 26.551 & 22.111 & 16.328 \\
\hline Maximum stress $\left(\sigma_{\max } *\right.$ average in "GPa" & 0.351 & 0.282 & 0.178 \\
\hline Elongation in $(\%)$ & 1.09 & 0.95 & 0.82 \\
\hline
\end{tabular}




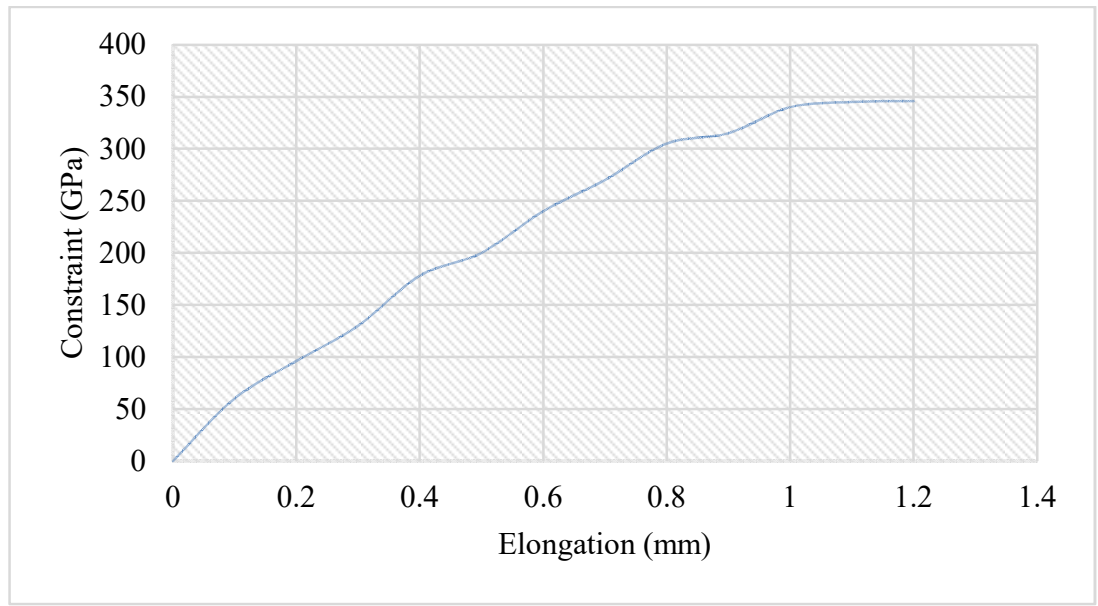

Fig. 2. Tensile stress as a function of the elongation for the 1 st specimen.

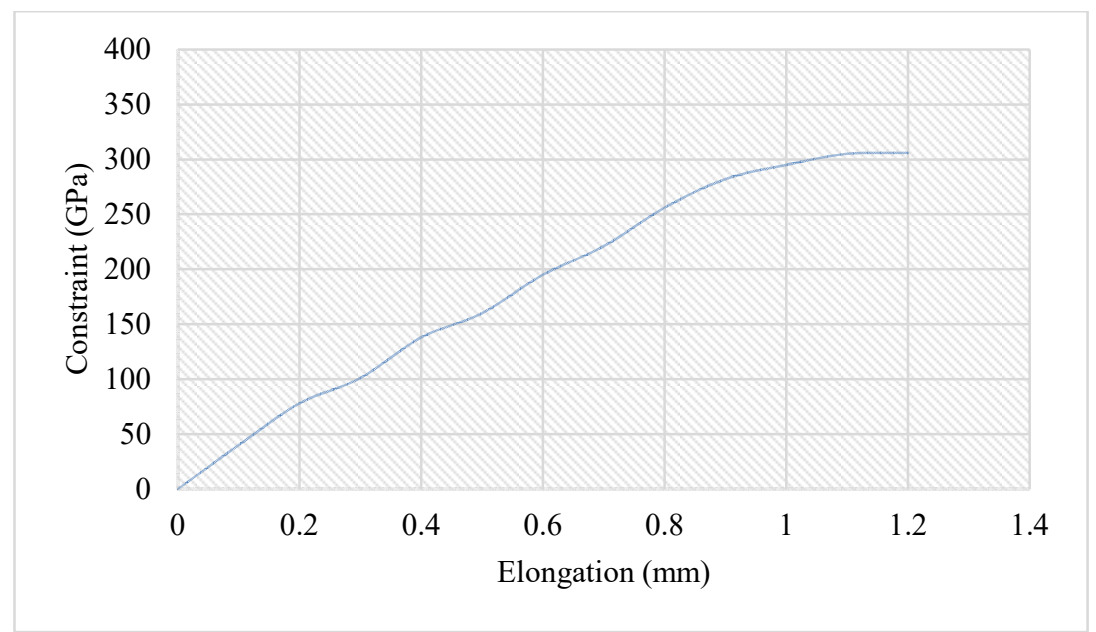

Fig. 3. Tensile stress as a function of the elongation for the 2 nd specimen.

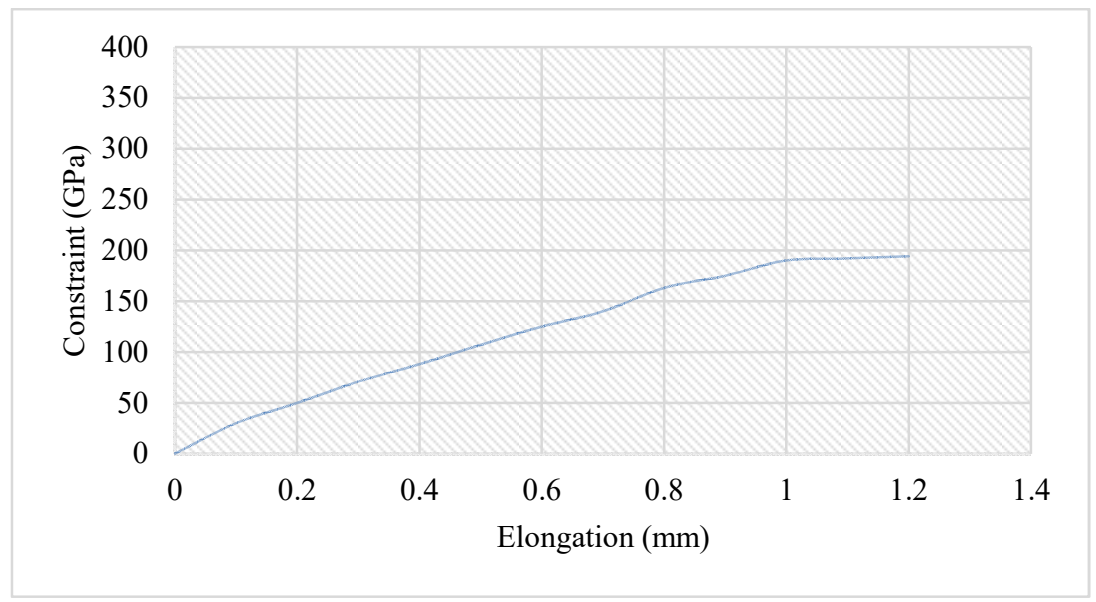

Fig. 4. Tensile stress as a function of the elongation for the 3rd specimen. 
By making use of obtained experimental results (Figures 2-4), we note that Young's modulus for specimen No. 1 (polyester resin + woven glass fibers) is $26,950 \mathrm{GPa}$, on the other hand, that of specimen No. 3 (polyester resin + non-woven glass fibers) is 16.418 $\mathrm{GPa}$, so that in the case of the first specimen the woven type fibers are long and oriented in the direction of traction which generates a tensile stress of $0.346 \mathrm{GPa}$.

In the case of the 3 rd specimen, the non-woven type fibers are short and randomly oriented, which generates a low tensile stress which is of the order of $0.188 \mathrm{GPa}$.

In the case of specimen $\mathrm{N}^{\circ} 2$ the YOUNG module is $22,611 \mathrm{GPa}$ because the latter is reinforced with fiberglass of the type (non-woven + woven) and therefore its mechanical characteristics are better compared to the $3 \mathrm{rd}$ specimen and less good compared to the first specimen.

Meraghni F. and Bezzazi A. [7-8] studied by acoustic emission the chronological development of damage in glass/polyester laminates and note that the first damage appears in the matrix (corresponding to the cracking of oriented strands transversely to the direction of solicitation). Then, when the deformation increases, the coalescence of the cracks in the matrix leads to the deboning of the interfaces.

\subsection{Three-point bending test}

The laminates obtained are cut into test pieces according to ISO 178 using a diamond disc.

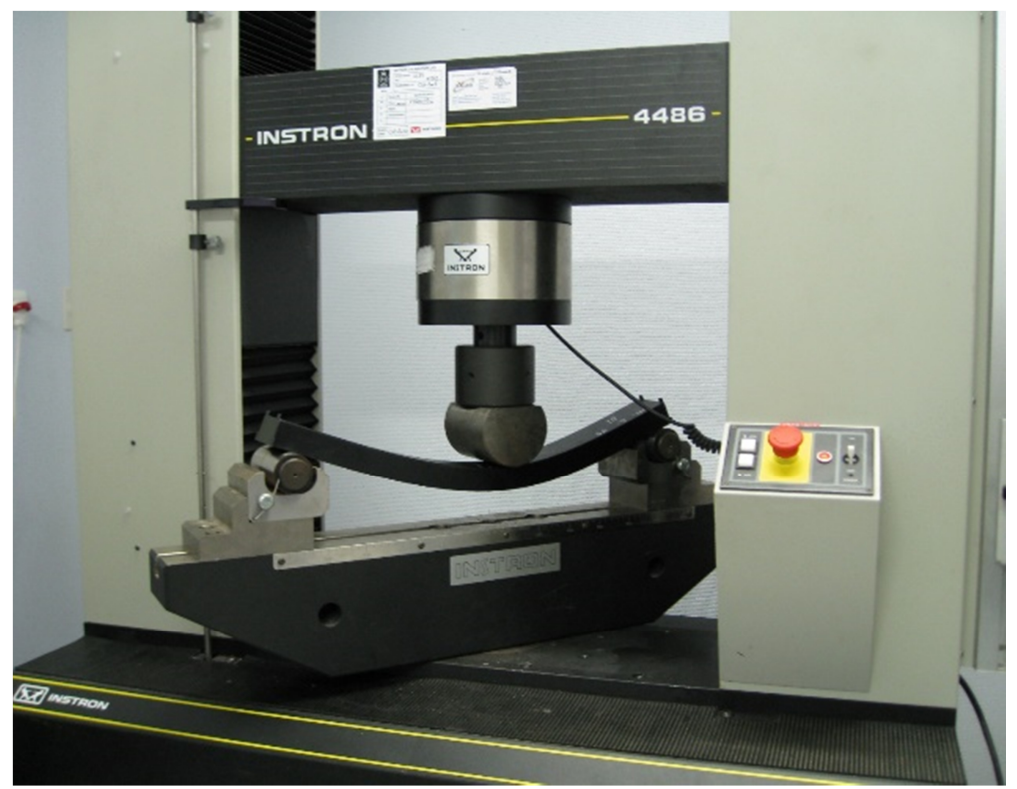

Fig. 5. Device for bending test.

Table 4. Mechanical features in 3 points bending test for specimens.

\begin{tabular}{|l|c|c|c|}
\hline \multicolumn{1}{|c|}{ Specimen No. } & $\mathbf{1}$ & $\mathbf{2}$ & $\mathbf{3}$ \\
\hline YOUNG module $\left(\mathrm{E}_{\mathrm{t}}\right)$ in GPa & 26.145 & 17.544 & 14.222 \\
\hline Maximum stress $\left(\sigma_{\max }{ }^{*}\right)$ average in "GPa" & 0.485 & 0.339 & 0.289 \\
\hline
\end{tabular}




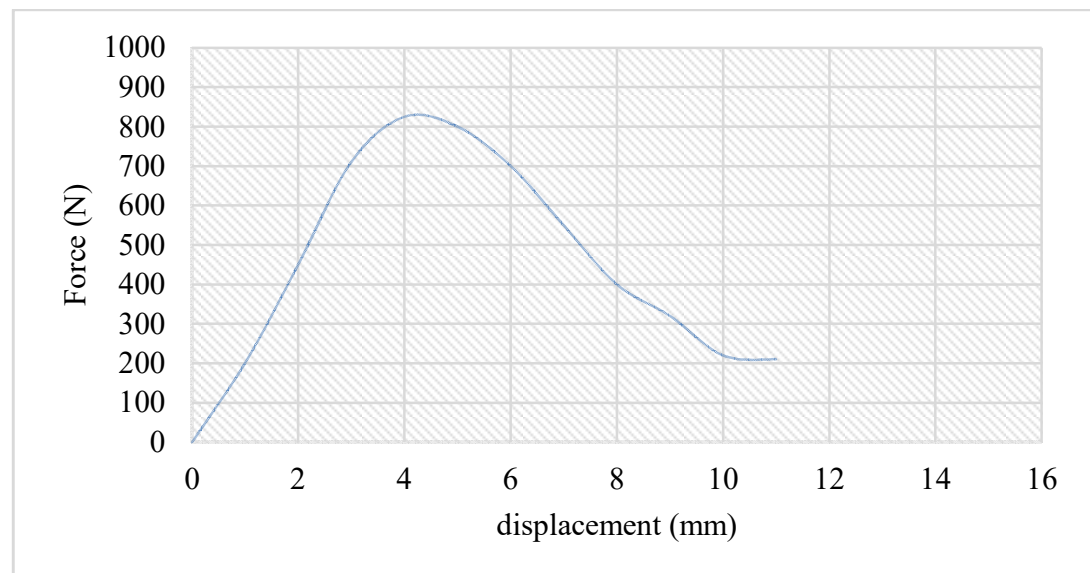

Fig. 6. Average force as a function of the displacement for the specimens subjected to 3-point bending of the 2 nd specimen.

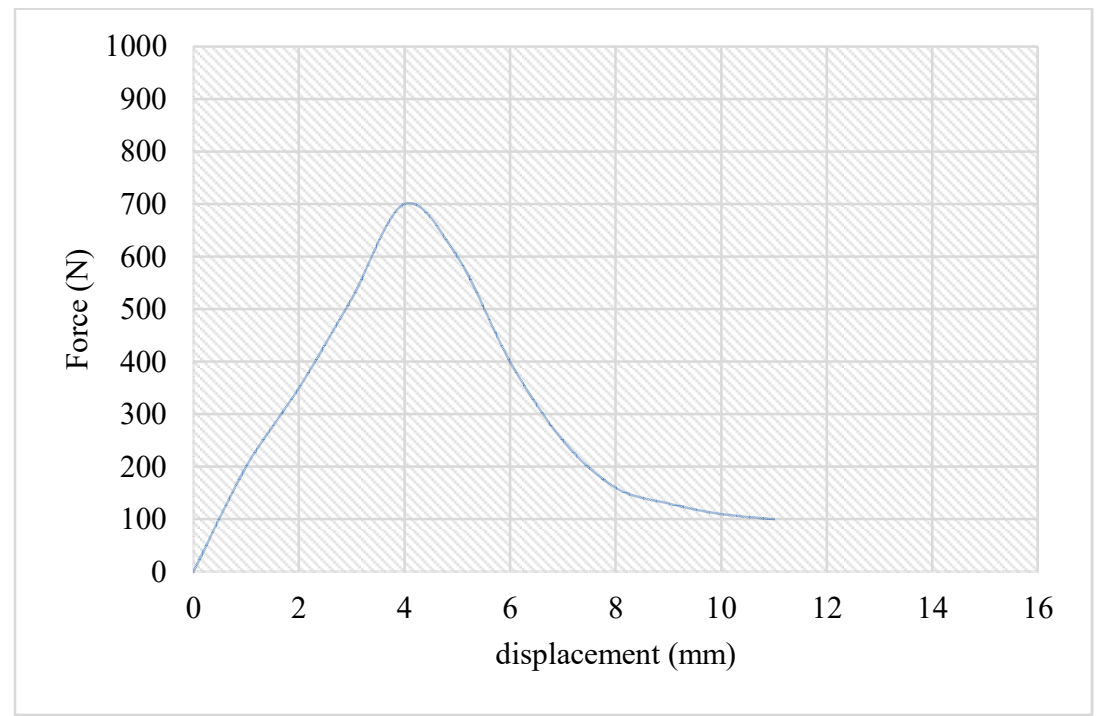

Fig. 7. Average force as a function of the displacement for the specimens subjected to 3-point bending of the 3 rd specimen.

The bending stress and the Young's modulus are calculated according to ISO 14125, by using of the following formulas:

$$
\begin{gathered}
\sigma_{\mathrm{F}}=\frac{3 F L}{2 b h^{2}}[\mathrm{MPa}] \\
\mathrm{E}=\frac{L^{3}}{4 b h^{3}}\left(\frac{\Delta F}{\Delta y}\right)
\end{gathered}
$$

Table 5. Results of the constraint calculation and the Young model for the three variables.

\begin{tabular}{|l|c|c|c|}
\hline \multicolumn{1}{|c|}{ Specimen No. } & $\mathbf{1}$ & $\mathbf{2}$ & $\mathbf{3}$ \\
\hline maximum force in "N" & 1122 & 931 & 722 \\
\hline Displacement at maximum force in "mm" & 4.554 & 4.129 & 4.134 \\
\hline
\end{tabular}


The analysis of the results obtained allows us to highlight the influence of a certain number of parameters on the behavior of the materials produced.

Influence of the type of reinforcement:

- specimen No. 1, the laminate reinforced with woven type glass fibers has a maximum stress of $0.465 \mathrm{GPa}$ and an elastic modulus of $29.645 \mathrm{GPa}$.

- specimen No. 3, the laminate reinforced with non-woven type glass fibers has a stress of the order of $0.279 \mathrm{GPa}$ and a module of $14.622 \mathrm{GPa}$. On the other hand, at the level of the strain at break one obtains approximately the same value.

- specimen No. 2, the laminate reinforced by 5 woven plies and 2 non-woven folds has a breaking stress of $0.349 \mathrm{GPa}$ and a modulus of elasticity of $17.144 \mathrm{GPa}$. These values are logical, between the values of specimens 1 and 3 .

Influence of the stacking sequence:

According to the work [5-6] The flexural failure of the different materials studied can be classified into two groups:

- specimen 1st: for this type of laminate, there are few transverse cracks. The material is damaged by breaking fibers in the compressed face preceded by delamination.

- specimens 2nd, 3rd: these two types of laminate are little damaged by transverse cracks and the rupture is mainly done by delamination between plies.

\subsection{Charpy impact test}

The test tube is placed horizontally in front of its supports, (Fig 8) is broken by a single percussion of a pendulum, applied at equal distance from the supports. The energy of the pendulum used is 25 joules.

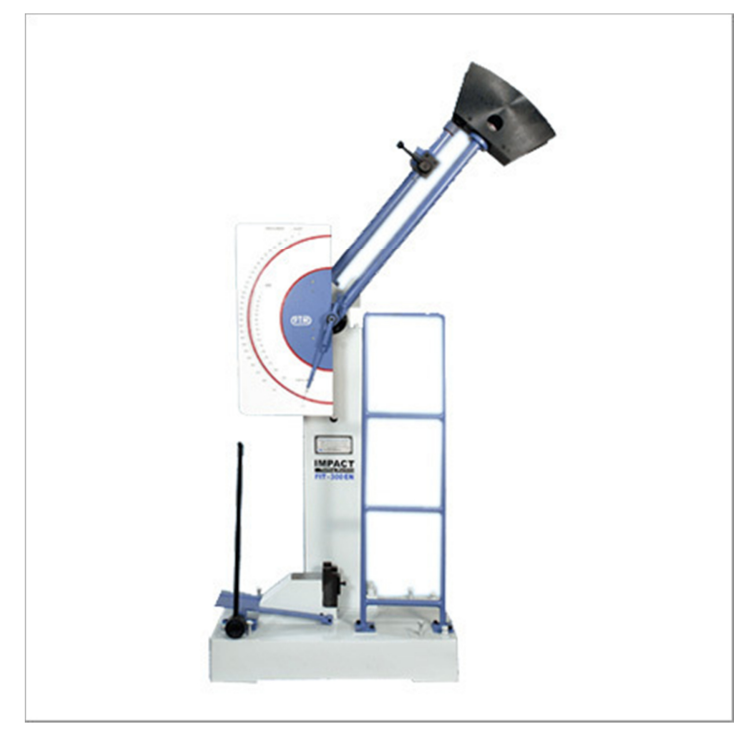

Fig. 8. Pendulum sheep for Charpy test.

Table 6. Breaking energy of Carpy test.

\begin{tabular}{|c|c|c|c|}
\hline Specimen No. & $\mathbf{1}$ & $\mathbf{2}$ & $\mathbf{3}$ \\
\hline breaking energy $\mathrm{Kj} / \mathrm{m}^{2}$ & 84.66 & 86.49 & 99.71 \\
\hline
\end{tabular}

From the experimental results (Table 6) we note that the breaking energy absorbed by specimen 3rd reinforced with glass fiber of the non-woven type $(100 \%)$ is of the order of $100.73 \mathrm{Kj} / \mathrm{m} 2$ per against specimen $\mathrm{N}^{\circ} 1$ which is reinforced with woven type glass fiber 
$(100 \%)$ absorbs a breaking energy of $83.86 \mathrm{Kj} / \mathrm{m} 2$, the breaking energy of the other test pieces is between these two values.

Laminates reinforced with non-woven type glass fibers have better Charpy impact resistance than laminates reinforced with woven type glass fibers.

\section{Conclusion}

The study devoted to study the mechanical properties of composite materials transformed from polyester resin and fiberglass leads to the following conclusions:

a) The use of conventional characterization tests (3-point tension and bending) makes it possible to highlight the influence of the nature of the glass fiber on the breaking properties of a laminate

glass/polyester. The results obtained show that laminates reinforced with woven type glass fibers have better mechanical characteristics in traction and 3-point bending, compared to laminates reinforced with non-woven type fibers.

b) The rupture of the composites is not instantaneous but it is the result of an accumulation of damage $[5,6,8]$. The results obtained show that the damage to the glass / polyester laminates is strongly influenced by the nature of the fiber.

In order to get closer to the stresses actually experienced by composites for naval use, Charpy impact tests were carried out on the three specimens. The results obtained show that laminates reinforced with non-woven type glass fibers are more resistant to impact, in contrast to laminates reinforced with woven type fibers which are less resistant to impact, therefore non-woven glass fibers type are the best placed for use in naval structures.

A study of the effects of the marine environment on the properties of the glass/polyester composite is interesting to see the influence of temperature and aging in seawater on the physic-chemical and mechanical characteristics of composite materials.

\section{References}

1. A. Karnoub, I.R. Antypas, A.G. Dyachenko, T.P. Savostina, IOP Conference Series: Earth and Environmental Science 403(1), 012162 (2019)

2. I.R. Antypas, G. Kharmanda, A.G. Dyachenko, T.A. Savostina, E3S Web of Conferences 116, 00002 (2019)

3. D.G. Aggelis, N.-M. Barkoula, T.E. Matikas, A.S. Paipetis, Composites Science and Technology 72, 1127-1133 (2012)

4. K. Aniskevich, A. Aniskevich, A. Arnautov, J. Jansons, Composite Structures 94(9), 2914-2919 (2012)

5. C. Varga, N. Miskolczi, L. Bartha, G. Lipóczi, Materials and Design 31(1), 185-193 (2010)

6. I.R. Antypas, A.G. Dyachenko, A.N. Sirotenko, S.A. Partko, T.P. Savostina, Earth and Environmental Science 403(1), 012005 (2019)

7. A. Bezazi, El Mahi, J.-M. Berthelot, B. Bezzazi, Strength of Materials 41, 257-267 (2009)

8. M. Ramesha, K. Palanikumar, K. Hemachandra Reddy, Mechanical property evaluation of sisal-jute-glass fiber rein (2013)

9. S. Markkula, H.C. Malecki, M. Zupan, Composite Structures 95, 337-345 (2013)

10. J.R. Correia, M.M. Gomes, J.M. Pires, F.A. Branco, Composite Structures 98, 303-313 (2013) 
11. X. Wang, L. Song, W. Pornwannchai, Y. Hu, B. Kandola, Composites: Part A 53, 88$96(2013)$

12. Y. Yoo, M.W. Spencer, D.R. Paul, Polymer 52(1), 180-190 (2011)

13. M. Ramesha, K. Palanikumar, K. Hemachandra Reddy, Composites: Part B 48, 1-9 (2013)

14. T. Sasayama, T. Okabe, Y. Aoyagi, M. Nishikawa, Composites: Part A 52, 45-54 (2013)

15. S. Markkula, H.C. Malecki, M. Zupan, Composite Structures 95(32), 337-345 (2013)

16. J.M.L. Reis, F.L. Chaves, H.S. da Costa Mattos, Materials and Design 49(33), 192-196 (2013)

17. J.R. Correia, M.M. Gomes, J.M. Pires, F.A. Branco, Composite Structures 98, 303-313 (2013) 